\title{
Affective bodying of mathematics, children and difference: choreographing 'sad affects' as affirmative politics in early mathematics teacher education
}

\author{
Anna Chronaki ${ }^{1,2}$ \\ Accepted: 19 March 2019 / Published online: 1 April 2019 \\ (c) The Author(s) 2019
}

\begin{abstract}
This paper responds to the frequently occurring phenomena of 'sad affects' experienced by student teachers as they confront the logic of 'proper mathematics' with young children of differently abled bodies. The notion of 'proper' entails a normalizing fixity of 'what counts' as mathematics for certain children and fails to recognize mathematics as a sensual encounter amongst bodies. The study draws upon Spinoza's notion of affect to consider the body's capacity to act, and makes the case for choreographing with body-movement, rather than disclosing, the politics involved in becoming teachers. It discusses how affective bodying with mathematics, children and difference in the classroom practice can be not only deconstructed but also reconstructed in affirmative terms, choreographically, as feeling and thinking-in-movement in ways that trouble and perturb the prevailing sharing of the 'sensible' in early childhood mathematics and in teacher education.
\end{abstract}

Keywords Early childhood mathematics · Teacher education · Affect · Sad affects $\cdot$ Body $\cdot$ Bodying $\cdot$ Feeling and thinking · Choreographing $\cdot$ Movement $\cdot$ Aesthetico-political pedagogy $\cdot$ Affirmative politics

\section{Introduction: confronting the logic of 'proper mathematics'}

Anna, Maria and Georgia, student-teachers in early years' education, knocked on my door in a state of distress. They had come from a local preschool where they had spent the morning devising the tasks for their upcoming teaching placement in mathematics. They felt despondent about their potential in teaching mathematics. Sighing, Anna said, 'We want to quit. We cannot continue. We are frightened of failing'. Their words were short and their bodies tense. There followed a silence, which was filled only with blushing cheeks and quiet tears. These were passionate students in the course and they had gone to the school with imaginative plans about how children might be playful with mathematical concepts such as space, area, number, and measurement. But their ideas had surprised the classroom teacher, who had seemed terrified at the vision of doing 'area' in the

\footnotetext{
Anna Chronaki

chronaki@uth.gr; anna.chronaki@mau.se

University of Thessaly, Volos, Greece

2 University of Malmö, Malmö, Sweden
}

preschool: 'This is preschool. How can you teach 'area' to such young children!? (...) this class includes Roma children and children with special needs. You cannot do proper mathematics with them'. On hearing this, the student teachers had become paralyzed with a fear of failure. The teacher's remarks policed what was sensible, and with whom, pronouncing them 'improper' on the grounds that children of a particular ability and race would be able to do only basic mathematics. The students were both confused and distressed at this closure of mathematical potential by the classroom teacher.

How might we respond to this event? It indicates the way in which discursive constructions configure certain bodies as able (or not) for mathematical activity, with significant implications for mathematics, children and difference. Entangled within this is the view of the 'expert' teacher as the gatekeeper of 'proper mathematics', requiring the nonqualified student-teachers to perform the classroom norms at the expense of creative experimentations. In this moment, their wish for an authentic encounter with children was demolished. Gabriel Tarde describes the subjection of the body to fear as follows: 
'The momentary paralysis of the spirit, of the tongue and limbs, that profound agitation descending to the core of one's being, that dispossession of self we call intimidation (...) It is a nascent social state that occurs whenever we pass from one society to another' (Gabriel Tarde, quoted in Massumi 2005, p. 31, emphasis in the original).

Whilst these student-teachers did not have to 'pass from one society to another', they did have to move across tense territories -moving from teacher education theory to the preschool institution and practice-based notions of "what works?' Such territories are dense with the politics of knowledge/power, which exemplify a 'will to power' as a will to judge, control and regulate (Nietzsche 1968). It entails the 'indignity of speaking for others' (Foucault and Deleuze 1980, p. 206) and is apparent in the way that the teacher guards the 'proper' order of things. It is sensed, bodily, as 'the unfolding reality of that fearful feeling' (Massumi 2005, p. 38), which intimidates them and renders them incapable to act. This focus on body can be traced to Spinoza's Ethics $(1677 / 1996)$, in which he argues that there is no feeling without a body.

Rancière (2010) discusses the logic of 'proper' as 'consensus', which '...defines a mode of symbolic structuration of the community that evacuates the political core constituting it, namely dissensus' (p. 188). It underlies hierarchical distribution of knowledge/power and delimits 'difference' for 'identity' by determining what is shared as common. In this realm '...everyone's speech is determined in terms of their proper place and their activity in terms of its proper function, without an aesthesis, or horizon of affects' (p. 189). This crossing of territories, for the student-teachers, was characterized by a desire to try out their own ideas. However, the confrontation with the expert teacher, who sought to police the 'proper' (based on idealized norms of childhood and mathematics), paralyzed them - they were engulfed by a fear of failure to perform according to institutional mandates. The aftermath of this encounter can easily become a reactive laboratory of 'sad affects', which, for Spinoza, are 'affects that close the event to its potential' or 'create a deadening, in the event, of what might come to be' (Manning 2016, p. 220).

The process of 'becoming teacher' involves 'sad affects' and it is vital for teacher educators to consider how this 'deadening' might be subverted. The transition between theory and practice can cause emotional ruptures, as student-teachers confront conflicting interests in the school context and also clashes within the novice/expert relationship (Zembylas 2003; Burman 2016). A recent review of research on mathematics teacher education (Ruge 2018) notes that prospective teachers face the violence of judgment as they struggle to adapt to these moments of transition.
This is further exaggerated in mathematics teacher education, where a nexus of modernist, neocolonialist and neoliberal discourses on curriculum-based teacher training unfolds hegemonic mandates requiring future teachers to develop into competent, flexible and self-regulated professionals (Chronaki 2009, 2011). They must learn to respond with ease to children, parents and colleagues while, at the same time, making 'proper' choices in 'consensus' as 'a new style of government' (Rancière 2010, p. 188). Simultaneously, children as young as 3 years old are called upon to become rational and creative problem solvers through an emphasis on 'high quality' mathematics education (Sarama and DiBiase 2004; Tsamir et al. 2011; NAEYC and NCTM 2002).

Such mandates for early years' mathematics are often opposed by teachers and teacher educators, who seek to problematize the uneasy fit amongst children, mathematics, and the socio-political agendas promoting child development as the mastery of reason (Walkerdine 1998). Discourses about the who of the 'child' and the what of 'mathematics' converge upon the subject as rational problem-solver. The situation is intensified when early years' teacher education is encountered through epistemic constructions of mathematics as a pure axiomatic field on the one hand, and of childhood as a protected period of life on the other. In this, a focus on mastering mathematics is perceived as harmful for a playful child. The possibility of imagining alter-relations between child and mathematics is further limited when subject/knowledge is infused with questions of race and ability, as in the example above. We can ask, here, how do student teachers dissent to the logic of 'proper' mathematics with young children while they become free to explore otherwise?

A common response to these issues is to encourage student teachers to turn reflexively to their own beliefs about mathematics and childhood. However, reflexivity alone cannot subvert 'sad affects' of knowledge/power in emancipatory terms. Massumi (2005) observes how reflection unfolds fear in perception: ' $(t)$ he unfolding reality of that fearful feeling has become the feeling of the fear enfolded in perception. The perception has been wrapped in reflection, and the reflection, in turn, has been taken up in memory. (p. 38). It is possible to see how such reflexive cycles might maintain a state of fear in student-teachers. Lewis (2018) argues how pedagogies that aim for anti-oppressive and emancipatory education often remain grounded in the intellectualist bias of a reflective practice, which is unable to address the asymmetry between mental beliefs and bodily actions. He focuses upon an affirmative reworking of bodily inscriptions of fear where '.. the full and immediate flow of perceptual apprehension is interrupted and replaced with hesitation' (p. 130). In a similar vein, the present paper discusses student-teachers' 'sad affects' in early mathematics education by considering their affirmative potential as affective bodying with mathematics, children and difference in the 
realm of classroom activity and choreographic creation. The paper is organized in six sections. Following the introduction, the second section considers research on embodiment in the context of mathematics education and cultural theory studies. The third section describes the setting of the study, the fourth and fifth analyze bodying with the mathematical concept of area in classroom activity and in choreography, whilst the sixth section offers concluding remarks.

\section{Opening up from body to bodying}

\subsection{The body in mathematics education research}

The idea of embodied cognition in mathematics education was mainly introduced by Lakoff and Núñez (2000). In their view, mathematics is a network of inferential abstract concepts, which are organized and grounded in the body through neuronal mechanisms, linguistic codes and gestures resonating with perceptual images, analogical reasoning, conceptual metaphors, and spatial representations. As such, mathematics is not a process of innate discovery, but rests upon cognitive training (Lakoff and Núñez 2000). In the same year, Châtelet (2000) published his philosophical thesis Figuring Space, in which mathematics is discussed as the virtual-actual interplay around the study of physical motion. According to Châtelet, bodily acts such as gesturing and diagramming become crucial to what he calls the 'amplifying' abstraction or the 'virtuality' of mathematics contributing enormously towards space reconfiguration. In this realm, mathematical activity appears to be intuitive and, at the same time, material and sensual. Whilst Lakoff and Núñez (2000) objectify forms of bodily gestures as cognitive representational structures, Châtelet (2000) conceives the generative force of bringing mathematics into being as inventive bodily motions in process (de Freitas and Sinclair 2014; Rotman 2009).

Over the decades that followed, numerous studies have expanded the body-mind unity through explorations of embodiment in mathematics teaching and learning (Arzarello and Robutti 2004; Sabena 2009; Radford 2009; Nemirovsky and Ferrara 2009; Gerofsky 2010; Roth 2013). While a research focus on bodily acts as semiotic systems abounds, a return to the body demonstrates a shift of emphasis from written and oral communication towards a recognition of non-verbal codes, by attending to how the body of the speaking subject speaks (Roth 2013, p. 202). Embodied mathematics is often approached as a container of gestures and bodily action that intentionally mediates mental constructions, cognitive schemas or esoteric images. The work of de Freitas and Sinclair (2014) problematizes such representational approaches of embodied phenomenology which tend to locate mathematical knowing in the body of an intentional, volitional and conscious subject, without addressing its relation with socio-material affordances. Along with Châtelet, they argue for the body's dispersion beyond its flesh (Deleuze and Guattari 1987) and propose a post-humanist perspective of school mathematics (de Freitas and Sinclair 2014). Despite such efforts, much attention to the body in mathematics education remains mostly captivated by the representational politics through a discursive mediation of classroom norms. There is a need to account for how the body becomes privileged or hindered by its human and non-human actors by considering its variable access in the cultural and political context of mathematical schooling. For this purpose, in the next two sections the body will be encountered as cultural product and process and the notion of affective bodying will be discussed as the body's capacity to act.

\subsection{The body as cultural product and process}

The body-mind distinction can be traced to the seventeenth century philosopher Descartes, who declared that he could exist without his body, claiming that personhood is distinct from physical presence. This Cartesian dualism contrasts the body as unruly, unpredictable, or emotional and the mind as abstract, rational and logical. Mind became associated with rationality and logic, establishing its ultimate projection into the world of mathematical sciences, whereas body became an undisciplined corporeal entity in need of enculturation (Merleau-Ponty 2012; Burkitt 1999). Spinoza (1667/1996), also writing in the seventeenth century, strongly denied Descartes's mind-body distinction and suggested a radical vision of the body as an affective amalgam of thoughts and feelings. Although ignored by his contemporaries, Spinoza's view of body has inspired recent discussions by Deleuze and Guattari (1987) as rhizomatic existence and by Manning and Massumi (2014) as affective body-movement-thinking.

The body is also explored by Bakhtin (1968/1984), studying the writings of Rabelais (c. 1494-1553), who narrated stories of medieval folk cultures and unofficial languages at carnivals, pagan festivals and marketplaces. Laughter, humour and brutality constitute the grotesque body as lived through the festive worlds of giants, monsters, dwarfs and fools. Bakhtin was aware that, due to cultural or religious morals, not everybody could experience their grotesque bodies; however, he was drawn to the body's regenerative force. He claims that the grotesque body, as opposed to a rational body, dispenses with the anxieties of bodily existence and has a direct and unmediated sensuous involvement with the world. In contrast, a Marxist viewpoint of embodiment reflects human beings who, fundamentally, work towards transforming and creating their own environment through labor that relates body and economy. Further, in the midtwentieth century Foucauldian studies of body-practices in 
the genealogies of sexuality, the prison system or the clinic, acknowledge how certain legislative or cultural forms of life (bios or zoê) become inscribed in the body as technologies of self (Foucault et al. 1988; Rose 1990). Here, the body is shaped and regulated through governing systems of surveillance, framed in material and discursive genres. The body is increasingly seen as a product of social constraints in the realm of specific languages (i.e., medical, psychiatric, managerial, educational, etc.) that tend not only to analyze, but also to control, discipline and regulate. This perspective can provide the impetus for the deconstruction of norms by unfolding procedures of biopower and biopolitics. It has, further, sensitized us to consider prevailing discourses of a mathematical body as serving to construct the body of the desired citizen as the alchemy of logic, reason and rationality (Walkerdine 1998; Popkewitz 2004).

The body evolves, also, as a process of becoming embedded in the ethical and political complexities of everyday or scientific techno-cultures where it strives to become socialized or enculturated, but, at the same time, resists, fails or escapes. Balsamo (1995) exploring gendered embodiments in cultural artifacts, argues how a body-technology image does not pre-exist but co-emerges within practices of producing cultural objects. She says: ' ...body and technology are conjoined in a literal sense, where machines assume organic functions and the body is materially redesigned through the application of newly developed technologies' (p. 3). In this, we realize how the body is not merely a representational means, a mediating device, or a regulating resource but preserves plasticity, speaks back, responds and, even, resists control or regulation. Butler's (1993) work on how the (gendered) body comes to matter offers a theorization of the body not only as being interpellated by law or regulated, but as being performed. For her, the body is 'a process of materialization that stabilizes over time to produce the effect of boundary, fixity, and surface we call matter' (p. 9) arguing that it is within this repetition that bodies become discursively constructed and materialized in language. She notes how the body comes to matter not only through performing the norm of law or culture but, also through failing to perform them.

However, Butler refutes the idea that a certain stylization of the body (i.e. style as the effect of symbolizing systems in a cultural and political structure) is an individual choice and stresses how we live by performing (or not) our physical bodies within institutional bodies. This view suggests that we are not entirely free, precisely because our bodies are not only the cause but also the effects of discursive, cultural and legislative frames. Following this idea, it is possible to observe the way in which the mathematical body comes to matter as a fixity within processes of materialization, where certain styles of being (e.g. following guidelines, sitting in rows, doing group work, solving problems, being accurate etc.) in the classroom emphasize the performance of 'proper' action as curriculum consensus. This involves a repetition (or its failure) and it is through processes of success (or failure) that certain bodies come to matter. It was through moments of feeling the fear to perform the logic of 'proper' that paralyzed the three student-teachers we saw in the paper entry. However, Butler claims that one must highlight a deconstructive potential to the statement that 'everything is discursively constructed' (p. 8). To deconstruct is also to consider the operation of exclusion, erasure, violent foreclosure or abjection as a discursive materialization of the subject beyond language (Butler 1993). Here comes the unruly body as seen above (i.e. grotesque, ab/normal, dis/abled) failing to perform the norm but, still, retaining its regenerative force and subversive potential. Butler explains how such failing results in melancholia, as a lurking sad affect in any minor subversion of the 'norm', that engulfs the possibility for a reconstructive potential as affirmative politics. In this light, the 'sad affect' acknowledges a 'trace of the other' through the need to give up any claim for the body's self-coherence, and thus any assumption that the body bows exclusively to discursive, cultural and legislative frames.

\subsection{The body's capacity to act in affective bodying}

A critical question here is how the body's failure to perform the 'norm' or, the body's incapacity to act, could be reworked in affirmative terms? Manning and Massumi (2014) provide inspiration as they move, with Spinoza, from what a fleshy body is, to what else the body can do in affective bodying with other bodies, movements and concepts. Their research-creation brings together in the laboratory entitled 'SenseLab' artists, philosophers and scientists to practice choreography as bodying that provides access to feeling-and-thinking-in-the-act. Their notion of bodying discusses the body as not a fixation of a gestural form, but as continuously taking form in relation to an ecology of practices in motion. They trust the compound of affect-bodiesmovement-thought as leading to 'what else a body can do' based on a Spinozist proposition of body as kinetic (moving) and dynamic (relating):

'A body, of whatever kind, is defined by Spinoza in two simultaneous ways. In the first place, a body, however small it may be, is composed of an infinite number of particles, it is the relations of motions and rest, of speeds and slowness between particles that define a body, the individuality of the body. Second, a body affects other bodies, or is affected by other bodies, it is this capacity for affecting and being affected that also defines a body in its individuality' (Deleuze 2005, p. 58). 
Manning (2016) discusses bodying so as to capture body as a fluid body-world ecology of affective relations in contrast to a volitional or intentional act. Manning and Massumi (2014) propose the bodying of events as the practice of feeling-and-thinking, thinking-in-the-act and movementin-thought in choreographic propositions. Such a proposition creates a plane of immanence that co-composes the intervals in-between bodies by stressing how the body remembers, extends its boundaries and becomes otherwise. This process is not about dancing in the classical sense, but it is, rather, for a chorus striving for the creative, sensual and political expression of feeling and thinking-in-movement. This perspective relates to Spinoza's understanding of bodies and minds, not as separate substances, but as relational modes, in which:

'...a mode is a complex relation of speed and slowness, in the body but also in thought, and it is a capacity for affecting and being affected, pertaining to the body or thought. Concretely, if you define bodies and thoughts as capacities for affecting and being affected, many things change' (Deleuze 2005, p. 59).

Thought becomes an active contributor in the bodying experience and the starting point for challenging the bodyworld distinction. Taking thought as complexly aligned across a relational field that includes body, mind and world, Manning (2016) turns to explore ways in which thinking is not subsumed within a conscious cognitive task (e.g. the mathematics of area) but becomes part of an affective bodying in the making. In this, the process of creating a choreography can be the study of thoughts in motion that unfolds the thinking of a concept's physical and material feel. As such, the thought, including the mathematical thought, can become a kinetic and dynamic part of affective bodying: 'To be affected is to go to the limit of what a thought can do' and '...thoughts are activities of relation that take time even as they make time, animated in the process of invention in the activity of living' (Manning 2007, p. 24).

In this context, affective bodying with the mathematics of 'area' is not merely a task of doing area as bodily action but, instead, takes the thought of area experienced as a kinetic and dynamic relation with others and explores the potential of co-composing an affective redistribution of the sensible in area through bodies. In this way, the feeling and thinkingin-the movement with area as affective bodying differs from the perspective of embodied mathematics where the body is discussed as a tool in mediating clarity in communication via bodily conceptual metaphors. Moreover, affective bodying is not focused on accounting for how bodies perform or fail to perform area, but instead on what else could the bodies do when area becomes a thought-in-movement. The question thus shifts from how a body performs a consensus with the logic of proper discursive figurations of the mathematics of area, to what modes of affects could be created out of its bodying with children and difference and, even, how such bodying might affect their bodies' capacity to act otherwise. Such affective bodying with mathematics, children and difference could entail an affirmative reconstructive potential. Below, the study's context, participants and phases are outlined.

\section{The study: context, participants and phases}

The study evolved as response to a fear of failure that often appears when student-teachers consider mathematical activity in the preschool classroom. The aim was to explore the ways in which affective bodying supports a reconstructive affirmative process of mathematical concepts, young children and difference. The study took place across two consecutive but interrelated phases, namely: Phase I, where the focus was on bodying as part of preschool activity, and Phase II, where emphasis was placed on bodying with mathematics as a process of creative choreographic propositions. Data collection evolved through first-person experience of being there with children, student-teachers and the teacher. It was based on participant observation, interviews, diary entries, videotaping and photographing the process of classroom activity and choreographing. Analysis focused on critical events that shed light on affective bodying.

\subsection{Contextualizing phases I and II}

Research took place in the autumn term of 2010 and involved 16 undergraduates, who volunteered across both phases. This paper focuses on the experience of three female student teachers Anna, Maria and Georgia who, as seen in the introduction of the paper, were distressed at the negation of their plans to teaching mathematics in the preschool. In Phase I, the student-teachers enacted their devised tasks in local preschool classrooms on concepts such as area, symmetry, number and polygons. In Phase II, their experience was revisited in a series of workshops in which affective bodying with mathematical concepts became the core for creating their choreographic propositions. In retrospect, although Phases I and II evolved in sequence, Phase II returned to events that were experienced in Phase I. Here we report on how Anna, Maria and Georgia's affective bodying with the mathematics of area moves from phase I to II.

Prior to both phases, the student-teachers were involved in coursework in which the devising of mathematical activity was discussed around haptic and digital material. In-between phases, they kept diaries and prepared oral presentations. During both phases critical events of affective bodying were documented in video and photos. In Phase II, such events 
comprised the digital archive of maths moves me: maths moves with me project that has expanded into a hybrid space of bodying with mathematical concepts and bodies.

\subsection{Being and moving across phase I to phase II}

Pondering discussions on the body as unruly (Bakhtin 1968/1988), failing to perform the norm (Butler 1997) or in affective bodying (Manning 2016) an ethical response in caring for my student teachers meant to encounter their sad affects as the politics of feeling and thinking in a body-world constellation including myself, institutions, children and mathematics. A first-person experience proved important as it is about belonging to the actual occasion of being there by being attentive to embodied relationality (Whitehead 1985; Manning 2008). As such, Phase I of the study focuses on being there with student teachers, young children and activity to explore affective bodying with school mathematics and its effects in our (in)capacity to act (see Sect. 4).

Soon after this phase, I had the chance to read studentteachers' diary notes and hear their oral presentations. I realized how any fearful feelings brought to my notice and experienced during classroom activity were concealed in both writing and oral genres. Despite experiencing sad affects, they opted not to disclose them publicly or they could not resort to language for articulating their reflections. Lewis's (2018) plea for a return to body resonates with a move beyond the current emphasis on discursive reflexive accounts of student-teachers' practice and aligns with bodying as conceptualised by Manning and Massumi (2014). In this realm, the move from Phase I to II came as a response to my urge to explore the affirmative potential of my student-teachers' sad affects, towards reconstructing their experiences. So, in Phase II of the study, they were invited to three workshops aiming to revisit thoughts and feelings experienced in Phase I using body movement this time. Although, none of the students were expert in choreography, dance or mathematics, they were engaged in the workshops not with the purpose of performing dance or doing mathematics, but to encounter their affective bodying with concepts, movements and bodies. This opened up a space to revisit their experience of classroom activity by reconstructing and composing its core elements into choreographic propositions (see Sect. 5).

\section{Phase I: bodying mathematics in classroom activity}

Here, the experience of bodying the mathematics of 'area', children and student-teachers in classroom activity is discussed.

\subsection{Bodies and the mathematics of area}

The classroom is located at a local preschool that regularly hosts student-teachers' practice. Children were lively and it felt comfortable to be there, despite the teacher's warnings for two boys and five Roma girls, who were perceived as naughty. Constructing children as lacking 'proper' behaviour is noted as common practice producing the dis/able and ab/normal body (MacLure et al. 2012; Henriques et al. 1984/2004). It further produced sad affects for studentteachers who feared their failure to perform 'properly' what was assumed as the classroom norm. Entering this cramped discursive territory, Anna, Maria and Georgia started the activity with the well-known story The Three Little Pigs. Devising materials for the notion of area the narrative focused on how the little pigs needed to decorate the bathroom floors in each house. They, then, asked the children: 'Can we help the three pigs to find out how many tiles they need to decorate their bathroom floors? Who might need the most tiles?' So, the concept of area was deployed as comparing and measuring surfaces with haptic models of the posed problem (i.e. orthogonal models of floors as surfaces, square tiles as units). Questions were as follows: Whose floor is bigger? How many tiles do we need to fill in each floor? And how many tiles are needed for all floors?

The children experienced area as geometric by comparing their floor models and filling them with square tiles. They were laying on the ground being in close proximity and working with the three floor models. Square tiles were placed one by one onto the models by the children who were trying to fill them up before they started counting the total number of tiles used in each one. When finished, they created rows of the square tiles used to fill in the floors. The length of each row noted the number of tiles used in addition also to indicating the area of the floor model. The children were immersed in a vital rhythm as if they were creating a mosaic or making a puzzle out of smaller elements. The tiles acted as counter units (or monads) on a canvas enabling the operative act of counting that evolved into rows of tiles. Some, but not all, grasped that this could happen on condition that each tile followed the movement of a geometric translation in a Cartesian mode of 2D plane transformation (i.e., a shifting move where every tile becomes an abstracted point and moves in the same direction and the same distance). Crucial for the fulfilment of this condition was for children to find a rhythm in which hands and tiles were coordinated. This involved the children refining their techniques in tiling and counting until they reached connectivity, order and accuracy.

The act of refining a technique has been noted by Manning (2016) in her work on dance choreography as a 'minor gesture that is capable of tuning technique to (...) its technicity' (p. 125). While technique is about enacting order 
and accuracy in a system of dance movement, technicity is a rigorous process that turns technique into art by pushing it to its limit and revealing its potential. In this sense, tuning a technique into its technicity seems also relevant for mathematics as in the case of area. Children were experiencing the concept of area through performing the techniques of tiling with square tiles the given floor models and counting the tiles in the Spinozian sense as both kinetic and dynamic modes (see Deleuze 2005, p. 58). In relation to a kinetic mode, children were using their bodies to localize and hone their techniques (Fig. 1). At the same time, children were making specific bodily moves of a dynamic mode relating with each other in order to refine and keep the rhythm in tiling and counting. I could hear them saying 'Be careful! Tiles cannot overlap! Place them in order' and 'When you finish, count how many they are. Count them all. But, once, not twice'. It was as if they realized the fragility of keeping the rhythm of tuning techniques into technicity over time and space. In this, the Roma girls were assertive, confident and successful in synchronizing their bodies (i.e. taking square tiles and placing them next to each-other without gaps or overlaps, counting carefully without losing any of the units, keeping track of counting). Noise was made as hands, legs and tiles moved at various speeds over the space, perturbing the classroom norm. Their feeling and thinking-in-movement via comparing, tiling or counting with the other children, was an affective bodying with the mathematics of area triggering them to overlook the teacher's attempt to regulate their bodies into being quiet.

Michalis, one of the declared 'naughty' boys caught our attention as he was excited to try out the materials and to begin tiling the floor models. He was tiling without keeping the strict condition of translating a tile on the Cartesian plane of floor models in order and accuracy. Instead, he was piling or folding tiles within the spatial borders of the model at hand. Soon, he lost the rhythm of tiling and counting, and looked disoriented. His early joy turned into frustration. I anticipated that my student-teachers would relate with Michalis but, although present, they could not face him. Encountering them in the presence of Michalis, I felt the enduring effects of the fear created in their first school visit. The configuration of the so-called high mathematics of area as 'improper' for a so-called 'disabled' child continued to block their capacity to act as becoming teachers. I took Michalis's hand in my own. Holding his hand with mine in affective bodying I continued the line of tiling and counting the tiles used as he gradually regained his lost rhythm.

Feeling and thinking-in-movement with area and Michalis, I sensed the logic and chaotic mode of his bodying with the concept of area that both resisted and desired a simultaneous tuning of tiling and counting in accuracy (see pictures 3-4, Fig. 1). One may wonder if there is any generative potential in Michalis's spatial dis/orientation as an anarchic arrangement of tiles. Derrida argues how 'The crisis of a rythmos broken by Being (...) is 'fundamental" in how literature 'shivers and flaps its wings' (cited in Plotnitsky 2003, p. 114) and Plotnitsky (2003) discussing algebras, geometries and topologies, explains how the perpetual presence of a rhythm crisis as a potentiality of chaos becomes a force for generating mathematical concepts. In other words, Michalis' quasi-mathematical experience of tiling the floor models is a manifold where geometric and topological elements of area break away from pure Euclidean space. Although, the floor models of the task urge children to engage with the axiomatic process of enacting area in a local 2D flat space, children's failures can move the task into unknown territories. The unknown hints an expansive understanding of area that includes its topological problematic and reminds us how the area of a land surface is not easily measured but subjected to a manifold smooth topology.

\subsection{Bodying area beyond the politics of normopathy}

Manning (2016) notes that the body is not always easy to handle. As seen above, while Michalis could not regulate his own body-motion to perform the techniques of tiling and counting in a 'proper' mode, the Roma girls performed in a vital rhythm of speed yielding bodily noise that did not fit a proper classroom. Their physical bodies disturbed desired norms (e.g. a quiet pace of moving, being polite, following rules in order, clarity and accuracy). Affective bodying with area was experienced in the realm of moving tiles along with moving their bodies, finding and losing a rhythm, creating chaotic moves and making noise. The teacher, often,
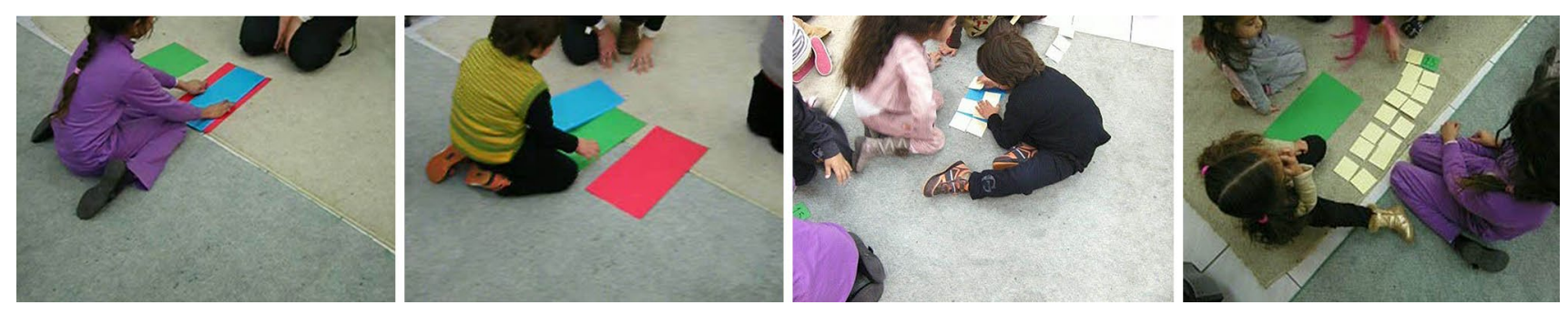

Fig. 1 Pictures 1,2, 3 and 4: Area with young children in the preschool (Roma girls and Michalis) 
felt she could not control their movement or regulate the rhythm in which techniques and technicity were enacted. In this context, the mathematics of area was avowed as not being proper for young children.

One may wonder what would have been the teacher's reaction if the student-teachers had proposed either a basic mathematical activity (e.g., counting from one to ten) or if the classroom was not such a diverse ecology of bodies. School mathematics is regularly constructed as the subject for the talented few producing difference and fear. It is important to note how children's bodies trouble the presumption of not-being-able to do mathematics, by being-able to perform it otherwise i.e., through bodying with materials and bodies in movement that do not always result in 'proper' modes of mathematical activity. Based on her work on bodymovement-thought, Manning (2016) argues that attention to affective bodying forces us learn to move below the assumed norm. This action constitutes a move beyond a normopathy that is organized around a linear view of development resting on neocolonial epistemologies of knowledge as neoliberal capital. The modern subject of school mathematics and technoscience is being inscribed as always developing into higher cognitive and social levels to reach above the "normal' in ways that configure, unproblematically, the desire of an independent, flexible and self-sufficient self (Chronaki 2011). With Manning (2016) I would like to propose how these views are '...based on a supposing strong knowing of where the body ends and the world begins -a frame that suggests the prevailing and seemingly unshakable triad of intentionality-volition-agency' (p. 112).

From a bodying perspective, one could argue how bodies are often unaligned and cannot perform as the intentional agent that scholars adhering with embodied mathematics assume (see Sect. 2). Bodies are, instead, in need of becoming part of emerging relations-in-forming. They need to be considered as bodying in the ecology of activity, which, for Manning (2016), means that we start not from a body-mind, but from a body-world grounding. Whilst the body-mind view implies attention at the individual, the body-world view explores how the body relates to a broader ecology inbetween bodies as socio-material arrangements. This view implies a move beyond gazing at the 'bodies' of Michalis, the Roma girls, or even the student-teachers, assuming they can accomplish an easy change to fit the norm. On the contrary, bodying suggests a relation with 'bodies' that troubles the norm by which they are judged and invests in the deconstructing and reconstructing of concepts through bodies that fail to perform according to the axiomatic order. Affective bodying in the classroom allowed us to sense that next to a child requiring attention, there is a student-teacher who needs to attend to a manifold of evolving relations. Walshaw and Brown (2012) report on the case of a teacher with 'acute sensitivity' who prioritizes affective support in creating a classroom pedagogy of share, care and joy by providing 'the means to participate in mathematics collectivity' (p. x). It is appropriate to ask here how an affective bodying with mathematics, children and difference could be considered as a reconstructive affirmative gesture for student-teachers, a move explored below.

\section{Phase II: bodying mathematics in choreography}

This section focuses on Phase II and explores the bodying of mathematical concepts as experiments with creative choreographic propositions.

\subsection{Bodying 'area' as a choreographic proposition}

The creative choreography had the aim of co-composing experiences of feeling and thinking with the concept of area in classroom practice. Anna, Maria and Georgia revisited classroom events in their choreography including their fear of failure provoked by the logic of proper prior to Phase I, and their encounters with children and mathematics during Phase I. In the first workshop, attention to touch and movement at varied speeds was practiced to overcome initial reluctance. Their reserved and hesitant bodies came in direct contrast with the vitality of children's bodies which urged a relation with other bodies-echoing the discussion of rational as ordered and accurate vs grotesque or chaotic bodies (Bakhtin 1968/1984). In the next two workshops the student-teachers were asked to focus on feeling and thinking area as movement for creating and performing a choreographic proposition that would unfold their bodying with children and mathematics in Phase I. In this context, Anna, Maria and Georgia were attending to how their bodies could move with the concept of area. Following Manning's (2016) notion of bodying as a chorus experimenting the intervals of movement and thought, they were exploring the in-between space of their moving with the concept of area. Their collective bodying was captured through video and photos in several steps. These visual captures enabled them to note the process of their thinking in movement intervals. After watching them perform their choreography, I identified three analytic themes; first, memory work of area in classroom activity, second, co-composition of events with area as thinking-in-movement, and third tuning techniques into technicity that compose choreographies.

First, memory work in classroom experiences was possible by asking student-teachers to revisit how children worked with area through questions such as the following: How did the children work with area? How did they move hands, legs, or full bodies in the task? How did the devised materials contribute to movement? How did they relate 
with other children? What made relations in-between bodies actual, possible, potential or virtual? Performing their memories as movement extended their thinking and feeling of area beyond axiomatic geometry. Second, their collective composing of area as comparing, tiling and counting in bodily acts became vital for their experimentations. The event of children's bodying with area became both the what and the how of their creations. The what stressed a return to area in experiences of difference, whilst the how focused on the virtual concept of area through body movement in the physical space (see Châtelet in de Freitas and Sinclair 2014, p. 201). In bodying, area became a kinetic experimentation with hands, legs, bodies, paper etc. and was animated through images of the body as surface and unit. The body was treated as surface whose area could be grasped by touching, sensing and feeling, whilst the foot, the hand or the tile became tools for identifying ordered relations with the surrounding space. In this way, they were not merely revisiting children's thinking of area on the flat plane, but they were grasping their thinking with area otherwise as a surface of smooth curvature. As such, bodying with the concept of area acted as a 'generative device' (de Freitas and Sinclair 2017), expanding their perceptions of spatial relations. Body movement with area involved: (a) comparing bodies as if they were surfaces, (b) spreading bodies around as if their bodies were units to cover space, or (c) extending the body into imaginable units to cover the body as surface (see pictures 5-8, Fig. 2). In this context, touch, movement as making steps, resting and running, as well as, capturing movement intervals through pictures and video became important parts of their co-composition process.

Third, the process of 'tuning techniques into technicity' (see Manning 2016) as body movement with the concept of area was core for their choreographic proposition (see pictures 5-8 in Fig. 2). Anna, Maria and Georgia became absorbed into refining body movement constellations figuring area. Their choreographic technicity grew into bodying around the Spinozian kinetic (the body moves with area) and dynamic modes (the body moves in relating to others) creating space to feel how body movement with the concept of area affects other bodies but, also, is affected by others (see Deleuze 2005, p. 58). The process of refining body movement was pertinent not only for creating a choreographic proposition but, mainly, for engaging in affirmative terms with a reconstruction of children's bodying with the concept of area in the preschool. The student-teachers' tuning of their bodily moves as 'techniques' in their choreography was directly related to children's own tuning of their bodily moves as 'techniques' in the classroom activity of tiling and counting (see phase I). As Anna, Maria and Georgia tuned their body moves, they needed to attend to children's bodying as feeling and thinking-in-movement through memory work. As Georgia wrote, returning via movement to children's bodying with the mathematics of area and letting their bodies become mathematics engaged them into appreciating the concept of area otherwise:

We felt as if we were being one and the same with them (i.e., children in classroom activity). We identified the multiple pieces of paper that we used to cover the surface of wood on the floor (...) by counting on the floor with our bodies and our bodies through our hands, we became connected in varied sequences (...) we could feel the passage from one step to the other, to the second and to the last. So, slowly but gradually we come to capture the mathematical concept. (Georgia, diary notes, Feb. 2011).

\subsection{Bodying as choreographing the political of 'a pedagogy of area'}

Plotnitsky (2016), based on how Deleuze and Guattari (1994) theorize the concept as not given but as perverted institutionally and self-posited, discusses the importance of attending to 'a pedagogy of the concept' as a pedagogy of creative thought. Following mathematician Riemann who argued that the reality of physical space remains unknown, he argues that mathematical concepts instead of urging the construction of exact representations in specific planes of reference, must retain openness seeking planes of immanence. They identify a creative potential of pursuing a pedagogy of mathematics as being inexact, in-accurate or, even, chaotic as it bares the invention of mathematical thought as manifold. Plotinsky claims that instead of pursuing a training in mathematics on either an encyclopedic or a commercial plane of reference which prevails in schooling, we must turn to a pedagogy of mathematical concepts and "(a)gainst this dominance, creative thought
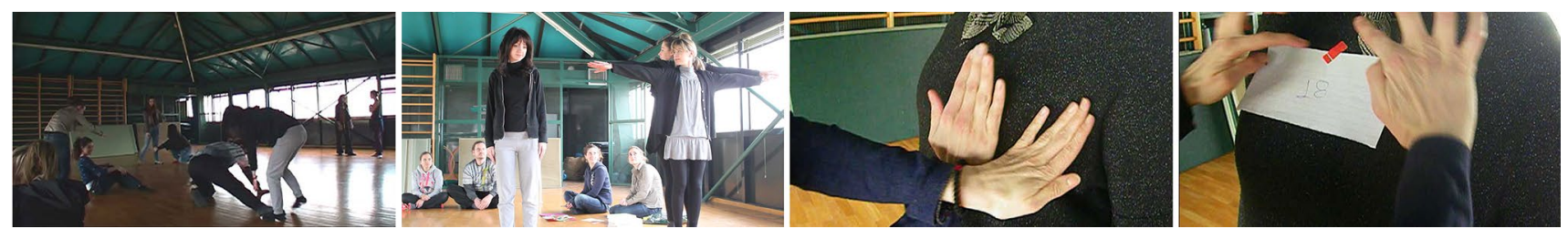

Fig. 2 Pictures 5, 6, 7 and 8: a choreographic proposition of bodying area 
must be kept alive' (p. 107). In a similar tone, Anna, Maria and Georgia, in their choreographic proposition, were bodying area as if they were attending to a creative 'pedagogy of area'. By actualizing the mathematics of area through body movement they preserve the concept's mobility in always new territories as they enacted 'a different sharing of the sensible' (Rancière 2004, p. 7). Thus, their contributions can be seen as acts of dissensus, troubling the politics of assumed consensus with a proper epistemic axis of area grounded in the norms of a Cartesian logic. But, how does such a pedagogy of area evolve as bodying?

A crucial aspect of a creative pedagogy of area through bodying mathematical concept, children and difference as noted by being with student-teachers prior to and inbetween Phases I and II, was that choreography provided a space for bodily acts that express a struggle between 'the movement of simulacra on the stage that is offered as material for the audience's identification' and the 'authentic movement characteristic of communal bodies' (Ranciere 2004, p14). A focus on student-teachers' ways of refining body movement allowed the body to acknowledge the process of capturing the concept of area in a nexus of relations amongst bodies, movement, thinking and feeling. Relations can often go unnoticed and as Massumi (2002) argues, the feeling of a relation cannot be large enough to be consciously registered, the relation itself being in turn too much to be contained in the limited range of perception. It is exactly in this space of feeling and thinking of relations that affective bodying unfolds the politics of their bodies (in)capacity to act. The student-teachers' choreographic propositions as memory-work of classroom activity involves a return to affective bodying in tracing the other by acknowledging the failures to perform the norm (see Butler 1997) as occasions of affirmation and subversion that allow one to interrogate the discursive im/proper around mathematics, children and difference.

Appreciating the mathematical concept as bodying in 'aesthetico-political acts' (de Freitas and Sinclair 2017) may mean that concepts 'are aesthetic insofar as they pertain to the senses' and they become political as they dissent to dominant normative alignments of mathematical activity. The present study demonstrates that the process of creating a choreographic proposition for the concept of area becomes a 'boundary-making practice' of 'some kind of different sharing of the sensible, where sensible refers to what is visible, auditory, intelligible' (de Freitas and Sinclair 2017, p. 86). As seen in previous sections, this 'different sharing of the sensible' enacted through affective bodying dares to reconstruct 'area' not only as an ordered flat space but also as a smooth unknown territory. This affective bodying retains a generative potential for the concept of area that choreographs the epistemic politics of 'proper mathematics' in the early years. Its affirmative gesture can be read as a creative pedagogy of area in the words of student-teachers:

The movement, the body movement affects to a great degree the capturing, the understanding of the concept (...) through the sense of touch we come in direct contact with our imagined objects (...) following the outline of one of the floor tiles we perceive its existence in the space and we realize the space it captures (Anna, diary notes, Feb. 2010).

A basic element to measure a surface was the sense of touch. Through touch we could perceive the boundaries of any part. From the floor to the ceiling. From one side of the room to the other. And from our feet to our head. In the end, we could determine the outline (...) using little paper-pieces gave chances through the sense of seeing to compare different shapes (Maria, diary notes, Feb, 2010).

I propose that the act of choreographing their affective bodying with mathematics, children and difference supports student-teachers in entering a pedagogy of area in ways that dissent the axiomatic of geometry as the only 'proper mathematics'. Amongst mathematicians, this is evident in experiences where the boundaries of geometry and topology blur producing what Leibniz and Riemann conceived as manifold. In Plotnitsky (2003) words:

'A manifold is a kind of patchwork of (local) spaces, each of which can be mapped by a (flat) Euclidean, or Cartesian, coordinate map, without allowing for a global Euclidean structure or a single coordinate system for the whole, except in the limited case of a Euclidean homogenous space itself. That is, every point has a small neighborhood that can be treated as Euclidean, while the manifold as a whole cannot' (p. 101).

The process of choreographing with mathematics paves a path for enacting and expressing a manifold space. On the one hand, it embraces the ordered rhythm of clarity and accuracy for creating a metric space, and, on the other hand, it encounters the generative potential of rhythm crisis in chaos as the condition for returning to a smooth bodyworld space.

\section{Concluding remarks}

Being responsive to sad affects in early childhood mathematics teacher education courses in ways that their reconstructive affirmative potential could be realised remains a challenging effort. In the present study, I do not wish to argue that creative experimentations in the form of choreographic art, as discussed here, could be a panacea for the pressing 
socio-political issues currently facing the body politic of mathematics education including the individual, cognitive, social and institutional 'bodies' of mathematics, early childhood, teacher education or early year mathematics. Questions of whether or how mathematical concepts, young children and diversity could come together and become investments in early year practices are complex and are, often, undetermined in the realm of conflicting discourses as they run the risk of promoting hurried provocative pleas of a yes or no dichotomy (Chronaki 2011, 2018). Beyond, a yes or no to an early mathematics education, I propose that an affective bodying with concepts, children and difference paves a path for a creative reconstructive pedagogy of mathematics in the early childhood teacher education.

The modest aim of the present paper has been to unfold how a return to the body as affective bodying in mathematics education might provide a response beyond the representation politics of body in language, identity and discourse. As seen in the two phases of the study, affective bodying allows to trace the other in what is assumed as 'proper mathematics'. It specifically, allows us to reconsider not only the ordered, but also the chaotic and the anarchic mathematics as it is operationalised in-between unruly, grotesque and different bodies in ways that perturb the 'norm' of mathematical activity as always oriented towards exactness and accuracy. Children's bodies expressed vitality, immersion, pleasure and joy as they experimented with the concept of area through their bodies, movement, materials and techniques in sensual ways. In contrast, the bodies of studentteachers were found as determined within prevailing discursive constructions of what is 'proper' in the preschool. These sad affects are often restricted to their body's capacity to act and relate to others. It was there that student-teachers' reflective work of mathematical activity with young children had to be enacted through bodying. As a result, their choreographing of classroom memories has revived them into becoming politically attentive to the kinetic (moving) and dynamic (relational) modes of mathematical concepts as a sensual affective experience with children and difference.

Open Access This article is distributed under the terms of the Creative Commons Attribution 4.0 International License (http://creativeco mmons.org/licenses/by/4.0/), which permits unrestricted use, distribution, and reproduction in any medium, provided you give appropriate credit to the original author(s) and the source, provide a link to the Creative Commons license, and indicate if changes were made.

\section{References}

Arzarello, F., \& Robutti, O. (2004). Approaching functions through motion experiments. Educational Studies in Mathematics, 57(3), 305-308.

Bakhtin, M. (1968/1984). Rabelais and his world. Bloomington: Indiana University Press (translated by Helene Iswolsky).
Balsamo, A. (1995). Technologies of the gendered body: Reading cyborg women. Durham: Duke University Press.

Burkitt, I. (1999). Bodies of thought: Embodiment, identity and modernity. London: Sage Publications.

Burman (2016). Fanon, foucault, feminisms: Psychoeducation, theoretical psychology and political change. Theory and Psychology, 26(6), 706-730.

Butler, J. (1993). Bodies that matter: On the discursive limits of'sex'. New York: Routledge.

Butler, J. (1997). The psychic life of power: Theories in subjection. Stanford: Stanford University Press.

Châtelet, G. (2000). Figuring Space: Philosophy, mathematics and physics. Dordrecht: Kluwer. (translated by R. Shore and M. Zagha).

Chronaki, A. (2009). Technoscience in the 'body' of Education: Knowledge and gender politics. In A. Chronaki (Ed.), Mathematics, technologies, education: The gender perspective, (pp. 7-27). Volos: University of Thessaly Press.

Chronaki, A. (2011). Disrupting development as the quality/equity discourse: Cyborgs and subalterns in school technoscience. In B. Atweh, M. Graven, W. Secada \& P. Valero (Eds.), Mapping equity and quality in mathematics education (pp. 3-21). Dordrecht: Springer.

Chronaki, A. (2018). The unbearable lightness of dislappearing Mathematics: Or, life and reason for the citizen at times of crisis. The Mathematics Enthusiast, 15(1), 8-35.

de Freitas, E., \& Sinclair, N. (2014). Mathematics and the body: Material entanglements in the classroom. Cambridge: Cambridge University Press.

de Freitas, E., \& Sinclair, N. (2017). Concepts as generative devices. In E. de Freitas, N. Sinclair \& A. Coles (Eds.), What is a mathematical concept? (pp. 76-91). New York: Cambridge University Press.

Deleuze, G. (2005). Pure immanence: Essays on a life. New York: Zone Books.

Deleuze, G., \& Guattari, F. (1987). A thousand plateaus. Minneapolis: University of Minnesota Press. (translated by Brian Massumi).

Deleuze, G., \& Guattari, F. (1994). What is philosophy? New York: Columbia University Press.

Foucault, M., \& Deleuze, G. (1980). Intellectuals and power: A conversation between Michel Foucault and Gilles Deleuze. In M. Foucault (Ed.), Language, counter-memory, practice: Selected essays and interviews (pp. 205-217). Ithaca: Cornell University Press.

Foucault, M., Martin, L. H., Gutman, H., \& Hutton, P. H. (1988). Technologies of the self: A seminar with Foucault. Massachusetts: Univerisity of Massachusetts Press.

Gerofsky, S. (2010). Mathematical learning and gesture: Character viewpoint and observer viewpoint in students' gestured graphs of functions. Gesture, 10, 2-3. (Special issue on multimodal communicative development), 322-344).

Henriques, J., Holloway, W., Urwin, C., Venn, C., \& Walkerdine, V. (1984/2004). Changing the subject: Psychology, social regulation and subjectivity. London: Routledge.

Lakoff, G., \& Núñez, R. (2000). Where mathematics comes from: How the embodied mind brings mathematics into being. New York: Basic Books.

Lewis, T. (2018).'But I'm not a racist!' Phenomenology, racism, and the body schema in white, pre-service teacher education. Race, Ethnicity and Education, 12(1), 118-131.

MacLure, M., Jones, L., Holmes, R., \& MacRae, C. (2012). Becoming a problem: Behaviour and reputation in the early years' classroom. British Educational Research Journal, 38(3), 447-471.

Manning, E. (2007). Politics of touch: Sense, movement, sovereignty. Minneapolis: University of Minnesota Press.

Manning, E. (2008). Creative propositions for thought in motion. Inflexions, 1(1). http://www.inflexions.org/n1_manninghtml.html. Accessed 28 Mar 2019. 
Manning, E. (2016). The Minor Gesture. Durham: Duke University Press.

Manning, E., \& Massumi, B. (2014). Thought in the act: Passages in the ecology of experience. Minneapolis: University of Minnesota Press.

Massumi, B. (2002). Parables of the virtual: Movement, affect, sensation. Durham: Duke University Press.

Massumi, B. (2005). Fear (the spectrum said). Positions: East Asia Cultures Critique, 13(1), 31-48.

Merleau-Ponty, M. (2012). Phenomenology of perception. New York: Routledge.

National Association for the Education of Young Children and National Council of Teachers of Mathematics. (2002). Position statement. Early childhood mathematics: Promoting good beginnings. http:// www.naeyc.org/resources/position_statements/psmath.htm. Accessed 28 Mar 2019.

Nemirovsky, R., \& Ferrara, F. (2009). Mathematical imagination and embodied cognition. Educational Studies in Mathematics., 70, 159-174.

Nietzsche, F. (1968). The will to power. New York: Vintage. (trans. Kaufmann, W. \& R.J. Hollingdale).

Plotnitsky, A. (2003). Algebras, geometries and topologies of the fold: Deleuze, Derrida and quasi-mathematical thinking (with Leibniz and Mallarme). In P. Patton \& J. Protevi (Eds.), Between Deleuze and Derrida (pp. 98-119). New York: Continuum.

Plotnitsky, A. (2016). Bernhard Riemann's conceptual mathematics and the pedagogy of mathematical concepts. In E. de Freitas, N. Sinclair \& A. Coles (Eds.), What is a mathematical concept? (pp. 93-107). New York: Cambridge University Press.

Popkewitz, T. (2004). The alchemy of the mathematics curriculum: Inscriptions and the fabrication of the child. American Educational Journal, 41(4), 3-34.

Radford, L. (2009). Why do gestures matter? Sensuous cognition and the palpability of mathematical meanings. Educational Studies in Mathematics, 70, 111-126.

Rancière, J. (2004). The distribution of the sensible. Bodmin Cornwall: Continuum. (Edited and translated by Gabriel Rockhill).

Rancière, J. (2010). Dissensus: On Politics and Aesthetics. New York: Continuun International Publishing Group. (Edited and translated by Steven Corcoran).
Rose, N. (1990). Governing the soul: The shaping of the private self. London: Routledge.

Roth, W.-M. (2013). On meaning and mental representation: A pragmatic approach. Rotterdam: Sense Publishers.

Rotman, B. (2009). Gesture and the'I' fold. Parallax, 15(4), 68-82.

Ruge, J. (2018). On epistemological violence in mathematics education research-An exemplary study in the Journal of Mathematics Teacher Education. The Mathematics Enthusiast, 15(1), 319-344.

Sabena, C. (2009). On the semiotics of gestures. In L. Radford, G. Schubring \& F. Seeger (Eds.), Semiotics in mathematics education: Epistemology, history, classroom, and culture. Rotterdam: Sense.

Sarama, J., \& DiBiase, A. (2004). The professional development challenge in preschool mathematics. In D. H. Clements, J. Sarama \& A. DiBiase (Eds.), Engaging young children in mathematics: Standards for early childhood mathematics education (pp. 415447). Mahwah: Lawrence Erlbaum.

Spinoza, B. (1677/1996). Ethics. Penguin Classics. (Edited and Translated by Edwin Curley).

Tsamir, P., Tirosh, D., \& Levenson, E. (2011). Windows to early childhood mathematics teacher education. Journal of Mathematics Teacher Education, 14(2), 89-89.

Walkerdine, V. (1998). Counting girls out: Girls and mathematics. London: Falmer Press.

Walshaw, M., \& Brown, T. (2012). Affective productions of mathematical experience. Educational Studies in Mathematics, 80(1-2), 185-199.

Whitehead, A. N. (1985). Process and reality. New York: The Free Press.

Zembylas, M. (2003). Interrogating 'teacher identity': Emotion, resistance, self-formation. Educational theory, 53(1), 107-127.

Publisher's Note Springer Nature remains neutral with regard to jurisdictional claims in published maps and institutional affiliations. 